\title{
Conception and Connotation: Carrying Capability of Creative Industry in Urban Microcosmic Form
}

\author{
Bo $\operatorname{Lin}^{1, a}$ \\ ${ }^{1}$ Tan Kah Kee college, Xiamen University, Zhangzhou, Fujian, 363123 \\ awellyuki@xujc.com
}

Keywords: Urban microcosmic form, Creative industry, Bearing capacity, Symbiosis

\begin{abstract}
The author defines the urban microcosmic form and makes a systematic analysis on the role of it in the development of urban creative industry in thesis. The author puts forward the concept of carrying capacity of creative urban microcosmic form and elaborates its connotation. Regarding urban microcosmic form as the carrier of urban creative industries development, the author brings up the view that the benignly symbiotic and interacting relationship between the urban environment and the sustainable power of the creative industries should be constructed, which could provide new thinking method and decision-making basis for the subdivision of creative industry contents in the aspect of urban micro-environment design.
\end{abstract}

\section{Introduction}

The concept of creativity is wide and open, which is conducive to the rapid spread of the new paradigm of urban development. The new information communication technology and the new logistics industry have created the new production system and the transformation of the structure. The creative industry, as a new industry trend and character, is widely accepted. With the rapid development of China's national economy, accelerating the process of urbanization becomes one of the goals of construction in China. China set up a creative industry research center in 2005. Since 2006, China has released the annual report of China's creative industries. From 2009, creative industries become part of China's national strategy and at the same time, the economic foundation and social environment of creative industries developed. So the concept of creative city has gradually penetrated into all aspects of the society and the relationship between city and creativity has become an important research area of urban economy.

\section{Research Background}

The English defined the creative industry for the first time in Creative Industries Mapping Document in 1998. Queensland University of technology established the first “creative industries faculty" in 2001, however, there is no clear descriptions and explanations of research field of creative industries, and the relationship between urban microcosmic form and creative industries is not involved in.

In recent years, foreign scholars have made researches on creative industries including the background of emergence of creative industries, the effect of creative industries on urban development, the significance to develop creative industries and the influence of developing creative industries on urban economy. They put forward a theory that city is the fulcrum of creative industries. For example, Michael Porter points that city is a good place for the success of commercial and industry competition. Charles Landry considered that city is a place of consumption, which reflects the development process of culture and economy. English scholar Florida made the relationship between urban form and the emergence of creative industries more clear. He held the view that to promote the creative industries, city must rely on "the social structure of creativity" to build an urban creative ecosystem. And he proposed the idea of the city atmosphere.

Charles Landry also made an important definition of the creative environment. Prior to that, Bianchin summarized factors which lead to the success of creative cities.

Whether the creative city can become a new paradigm of urban development is still a debate in 
academic circle, however, the inner structure of the creative city is an objective fact. That's to say, creative environment and cultural creative industries are interrelated. And as the rise of new economic sectors, their interrelation becomes common phenomenon and trend, which defines the new type of new urban economic development and urbanization in theory.

Traditionally, extensive outline of street and internal self construction form are mixed in China's urban microcosmic form (Wang Jinyan, 2005). However, the expressions of urban microcosmic are different. The wordings we often see are "city scape" (Wang Dehua, Wang Jinhui 1982) and "street view"-commonly used in Architecture and urban planning (Du Baicao, 1981). Though "street view" firstly used in research of urban roads, these two wordings' research field and objects belong to the same research range.

There are also some research findings on the relationship of the creative industry and the city. More scholars explored and proposed bottleneck and development opportunities of urban creative industries, explored the conditions for urban creative industries to emerge, studied that creative industries support environmental evaluation system, explored ways of development of urban creative industries in terms of cultural identity, geographical characteristics as well as the historical development, and also cited a number of cities that change form in order to achieve the double harvest of creative industry development and urban renewal, like the reuse of industrial heritage in Changzhou(Zhang Wenjun, Shao Junying, 2008).

Many aspects have not been involved in domestic and foreign research at present:

First, the practice of creative city is at the stage of exploration so urban microcosmic form is not regarded as one of bearing factors of creative industry in city's development, while it is particularly important to establish suitable style and level of creative industry for city.

Second, as for the city's image and space design, the city is a kind of material and cultural carrier in the concept. The symbiotic interaction of urban microcosmic form, city atmosphere and continued momentum of creative industries is not included in the study.

Third, under new technologies and new requirements, the new project like endogenous development dynamics of urban space does not go deep into the field of creative industries which is a long-term strategy.

\section{The definitions of key concepts}

In this thesis, the author defines the microscopic form of the city as: different from the macro form in the urban regional planning, it refers to the necessary urban landscape and physical characteristics, comprehensively composed by the city streets, buildings, facilities, public space, and historical landscape, etc, which must be able to let the vast majority of urban residents (including residents and tourists) appreciate, recognize and identify.

In this thesis, carrying capability of creative industry includes followings:

1. Neighborhood of the city must be conductive to expand creative industries activities;

2. The characteristics of urban regional features must be able to achieve cluster development of creative industries;

3. The urban microcosmic form must fit specific type of creative industries;

4. The public space of city has strong creative atmosphere;

5. The quality of urban impressions in urban microcosmic form must be able to attract creative talent.

The article tries to research the carrying capacity of creative industry in urban microcosmic form. It includes five parts.

First, it researches the comprehensive perception of block to city innovation;

Second, it studies if the area of concentration is formed when the features of city influence creative industry;

Third, it researches the connection between the style of creative industry and urban microcosmic form;

Fourth, it researches the innovative atmosphere of public areas; 
Fifth, it researches the prerequisite of urban microcosmic form gathering innovative human capital.

The research framework of carrying capacity of creative industry in urban microcosmic form is as follow:

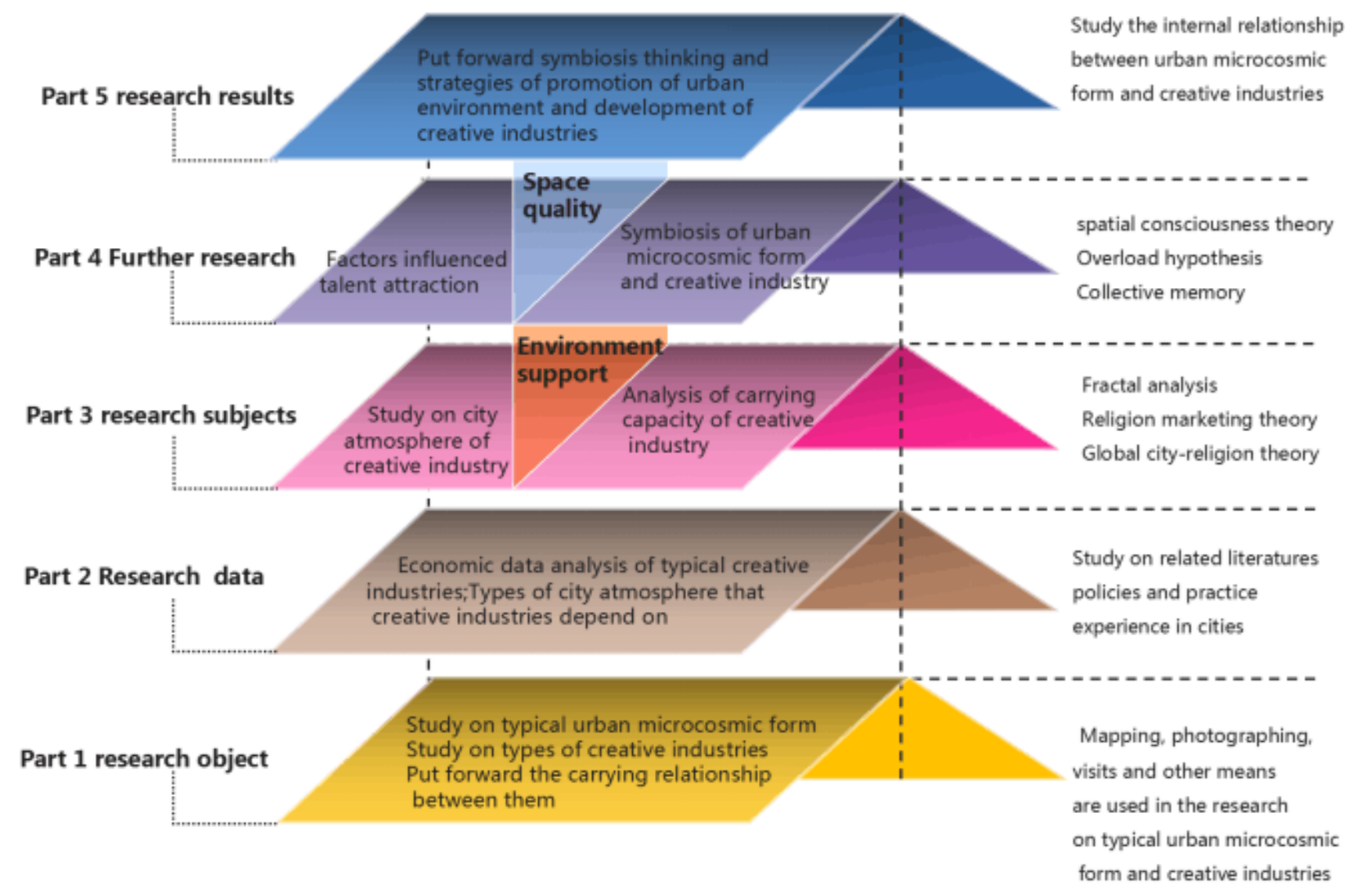

Fig. 1 Research Framework Sketch Map

To develop creative industry is a way of city's economic transformation. Creative industry is a kind of derivative economy in urban renewal system. Therefore, urban microcosmic form as an important carrier of urban renewal could reflect the personality and character of city and form the carrying capability of creative industry. So, different cities and even the same city in different times, the carrying capability of creative industry in urban microcosmic form is different.

The constructions of urban microcosmic form and creative industries are two important dimensions of urban construction in new normal state. The growth of urban micro form and development strategies of creative industries will affect the formation of the characteristics of urban morphology and the healthy development of creative industries and they are important factors in the city's creative index system.

Decisions of urban detail image construction, creative economy and talent accumulation of creative industry must be made in compliance with the urban microcosmic form and cultural connotation. With the development of urban economy, industrial environment must be improved from the perspective of regional urban environment, which is the inevitable choice for the development of industrial economy and urbanization.

Our country leads a unique way of urban development and the urban form contains its own connotation as well. To achieve the urban economic transition with the help of urban creative industries, evaluating and supporting the bearing capacity of creative industries is the first step. Meanwhile, how the urban spatial construction conforms to the developing tendency of creative industry should be considered and the history of urban micro form respected. That will lift the city brand to a new level.

Economic characteristics of the city also depend on urban structures and social characteristics. These structures and historic features, is one of the important reference indicators to new state urban construction policy. 


\section{Research Aims of Carrying Capacity of Creative Industry in Urban Microcosmic Form}

The thesis analyzed urban microcosmic form's limitation and promotion to local creative industries from the perspective of carrying capacity and discussed how to enhance the city's space quality and connotation in the establishment of urban microcosmic form and development of creative industries.

The thesis discussed on integration and the formation of ideas and policies of urban construction and development of the creative economy from the perspective of creative city.

The thesis integrated the urban creative atmosphere and talent attraction into the research category of carrying capacity of creative industries and enriched the theory and research dimensions of urban creative industry and urban transformation.

\section{The Innovation of This Concept}

The concept study in this thesis is a cross-disciplinary of urban economics and environmental design research, and the innovation lies in:

1. Changing our thinking of developing creative industry to promote the creative economy into reverse dimension that increasing the effect in urban microcosmic form to creative industry activity which relying on the city environment in order to give impetus to the development of economy and renewal of the city.

2. Linking urban planning, architecture, industrial economics and environmental aesthetics to discuss mutually beneficial system of urban public space, urban creative activities and creative economic development.

3. Combining opportunities for city construction in the new era and different types of urban environmental history forms and styles, as a prelude to a new research field.

\section{Conclusion}

Compared with studies on urban special form in China and practice of thriving creative industries, the studies on the subject that whether urban microcosmic form could develop creative industries according to local conditions or even on the subject that whether urban microcosmic form is able to promote the achievement of creative industries is not so popular in academia. In this paper, the definition of concept and the research field of it can make up this gap. Different from diversified constructions of creative city in Europe, the construction of creative city in China is more government-led and policy-oriented. The concept proposed in the paper offers groundbreaking guidance to research on the carrying capacity of creative industry in China, and supports the formation of the symbiotic relationship and the positive interaction between urban microcosmic form and the internal demand of creative industries. The concept is of theoretical and practical significance to the development of city especially for urban design and city construction from the perspective of the creative industries and creative economy development. It can also provide a new way of thinking and decision-making basis for the subdivision of creative industries in the micro design of the city.

\section{References:}

[1] ( UK)Charles Landry.Translated by Yang You lan.The Creative City: A Toolkit for Urban Innovators.Beijing: Tsinghua University press， 2009:168

[2] Le Zheng.Blue Book of Shen Zhen•Annual Report On Cultural And Creative Industries Of Shenzhen And Hong Kong(2010).Beijing: Social Sciences Academic Press(China),2010:270

[3] Hu Bin,Chen Chao.Development and Creative industries and place Marketing.Shanghai: Shanghai University of Finance and Economics Press,2014:216

[4] Zhang Jingcheng.Chinese Creative Industries Report.Beijing: China Economic Publishing 
press,2015:15

[5] Tang Yan,(GER)Klaus R.Kunzmann.Creative Cities in Practice:European and Asian Perspective,2013(in Chinese)

[6] Liu Yao.Micromorphology Studies of Conzenian School and Its Application in the Conservation to Historical Townscapes.Urban Insight,2014,05(in Chinese)

[7] Yang Tao.Space Syntax: Meso- and Micro- Urban Morphology under the View of Graph Theory.Urban Planning International,2006,03

[8] 中华人民共和国住房和城乡建设部.中国城市建设统计年鉴 2014[M] .北京：中国统计出版社, 2015:60(In Chinese)

[9] (ITA)Camilla Costa.Translated by Zhou Jing .Creative City Development In Globalization Process. Planners. 2012, 04(in Chinese)

[10] Huang Haijing,Chen Gang,Style Control of Urban Waterfront Based on Fractal Theory:A Case Study on the Two Rivers and Four Zones of Chongqing.New architecture,2015,03(in Chinese)

[11] Andersson,AE(1987)Culture, creativity and Economic Development in a Regional Context, Strasbourg: Council for Cultural Coopreation, Project No.10, Seminar No. 5.

[12] Unesco,Global Alliance For Cultural Diversity.Understanding Creative Industries: Cultural Statistics for Public Policy Marking. Pairs:UNESCO,2006.

[13] Landry C. The Creative City:A Toolkit for Urban Innovator.London:Earthscan,2000.

[14] Cook P, Lazzeretti L(ed.).Creative Cities,Cultural Clusters,and Local Economic Development. Cheltenham: Edward Elgar,2008. 